\section{THE GUATTARI ATMOSPHERIC TELEGRAPH}

THIS new invention is stated to consist of certain arrangements and combinations of apparatus whereby ordinary air compressed and passed through a tube, is utilised as a means of communicating intelligence from one given point to another, effecting the same object as the electric telegraph.

The principal portion of the apparatus consists of a reservoir or air-vessel which is charged or filled with air compressed to any desired degree according to the initial velocity or force which it is requisite the movements of the air employed should possess. A double action compression pump, or any other suitable mechanism, may be employed to charge the reservoir or air-vessel, and to sustain the pressure to the required degree. The reservoir or air-vessel is connected by means of a tube or pipe with a writing apparatus of any suitable description, and such as are well known and understood, especially in connection with electro-telegraphy; the tube or pipe being provided with a cock by which more or less force may be given to the current of air whereby the writing mechanism is actuated. In order to regulate the signals, a governor or piston, actuated by hand, is employed, by which pulsations or movements of the air in the tube or pipe are transmitted through a valve which is arranged therein, the currents actuating a lever connected with the writing apparatus. For the purpose of giving or receiving signals, the before-mentioned tube or pipe is connected with a conducting tube or pipe constructed of any suitable material, and which is so arranged that communication can be established between the air reservoir, or vessel, and the writing engine which is placed at the receiving station, or vice versa, by means of stop-cocks which are worked by hand. An indicator is employed to show the force of the current of air passing through the transmitting tube or pipe. Similar arrangements are, of course, placed and employed at each end of communication. By means of this invention it is stated that intelligence and signals can be transmitted to any distance; any of the known receiving and recording instruments capable of being used in connection therewith being employed. It is obvious that any number of conducting tubes may be employed, the requisite currents or pulsations of air therein being produced as before mentioned. The Guattari system claims to be more simple than the electric system, both in point of construction and continuous use, for whereas in the latter case it is necessary to use the electric battery and all its accessories, by the former ordinary atmospheric air compressed will perform similar functions. It is also claimed for it that it is free from atmospheric influences, which it is well known materially disturb the electric telegraph on the occasion of storms; and that the tubes employed as the medium for conducting the air would not be subjected to accidents like the ordinary wires, and would therefore necessarily last longer, and thus prove much more economical. We understand also that it is so simple that any person may learn in a few hours how to use and work it with the greatest ease, as compared with the electric system; it is calculated that the machinery necessary to work this system could be produced at about one-half the producing and annual working cost of the electric system.

The Royal Scientific Institute of Naples has already awarded to Signor Guattari a gold medal in recognition of what they consider an important invention, adding a graceful tribute on its presentation to the effect that it was the only gold medal which the Institute had ever awarded. The following experiments were made on Monday, i th July, r870 :-

I. Transmission by atmospheric compression by means of the large machine, obtaining answers by impulsion and repulsion, Signor Guattari having at present but one machine.
2. System of impulsion and repulsion by a naval apparatus, which may be used with fiye different derivations or branches.

3. Universal telegraphy, namely, despatching telegrams to one or more stations at the same time without the aid of the transmitting machine or the necessity of the sender remaining fixed to any one point.

\section{ON DEEP-SEA CLIMATES*}

RECENT investigations have certainly tended to R confirm the view originally advocated by my colflat a large portion and continuously accumulating sediment, at all events since the commencement of the "Cretaceous period," and possibly much earlier. The marked parallelism which, setting aside all local dislocations and denudations, evidently exists between the Jurassic, the Cretaceous, the Tertiary formations, and the present sea-board, and the evident relation of that parallelism to the older rock axes, would seem indeed to indicate that the main features of the present physical geography may date from a period even anterior to the deposition of the older Mesozoic rocks. With many minor and temporary oscillations, of which we have ample geological evidence, the borders of the Oolitic, the Cretaceous, and the Tertiary seas, have apparently been successively and permanently raised, and the ocean over an area, the long axis of which may probably correspond with that of the Atlantic, proportionally contracted. The question simply is, whether, since the elevation of the Jurassic beds, any oscillation has at any time raised into dry land the whole of the trough of the Atlantic, so as to arrest the deposit of sediment abruptly over the area, and to extinguish all animal life, thus defining what seems to be popularly understood as the close of a geological period, and requiring the complete repeopling of the succeeding sea by immigration, or, according to another view, by the creation of an entirely new fauna. It seemed to us on the whole more probable that the successive elevations of the borders of the Mesozoic sea were accompanied by compensating depression and deepening of the centre of the trough, which may thus have been inhabited throughout by a continuous succession of animal forms ; at all events, the onus of proof appeared to rest with those who maintained any breach of continuity,

The deep-sea dredgings on both sides of the Atlantic have brought to light a very large number of hitherto unknown animal forms, and undoubtedly the assemblage bears a decided resemblance to the fauna of the chalk-a resemblance which increases as the investigation proceeds. Probably the most striking point is the apparent identity of the material of the chalk with the chalk-mud of the Atlantic; the globigerinz and coccoliths by whose accumulation the beds have been, and are now, being produced, seem to be the same; though, of course, it is difficult to determine with certainty the specific identity of such simple and variable forms. Sponges are abundant in both, and the recent chalk-mud has yielded a large number of the examples of the group porifera vitrea, which find their nearest representatives among the ventriculites of the white chalk. From Prof. Martin Duncan's report it would appear that the corals, which are chiefly confined to water of moderate depth are most nearly allied to those of the later Tertiaries: The echinoderm fauna of the deeper parts of the Atlantic basin is very characteristic, and yields an assemblage of forms which represents in a remarkable degree the corresponding group in the white chalk. Species of the genus Cidaris are numerous; some remarkable flexible forms of the Diademidæ seem to approach Echinothuria. M.

* The substance of a Lecture delivered to the Natunal Science Class in Queen's College, Belfast, at the close of the summer session, July $15, x^{8}$ o. 